\title{
Constellations of (In-)Convenience:
}

\section{Disentangling the Assemblages of Canada's West Coast Island Mobilities}

Modern socio-technical assemblages of mobility (Graham 2002), such as ferry systems, allow us to move in ways that our bodies alone could not, therefore making movement more convenient. But while these assemblages enable us to reach our destinations easing the burdens of physical movement, they also force us to confront unintended, unplanned, and controversial consequences (Tanner 1997). For example, modern ferry boats afford islanders the potential to quickly access mainlands and other islands, but their use also rubs against deeply rooted affective orientations - such as the complexities of the "living contradiction[s] between openness and closure' typical of islands (Baldacchino 2007a: 5). Examining mobility technologies in ecological (Ingold 2000, 2007) and relational terms (Adey 2009; Bissell 2009; Cresswell 2010) ought to allow geographers to understand how technological assemblages' operations are embedded in complex and often contradictory and conflicted definitions of space and movement. In this paper I focus on such ecological/relational configurations with the broad objective of examining the politics of island mobilities.

Drawing from fieldwork in islands and coastal communities of British Columbia (BC), Canada, this paper focuses on three elements of mobility technology assemblages: frictions, motives, and costs. In doing so, I interpret the local experience and politics of ferry mobility constellations. Mobility constellations are 'particular patterns of movement, representations of movement, and ways of practicing movement that make sense together' (Cresswell 2010: 18). Mobility constellations are historically and geographically specific 'entanglements' whose analytical and empirical disentanglement requires a focus on speed, rhythm, route, feel, motive, and friction (Cresswell 2010). In what follows I disentangle two of these elements, friction and 
motive, as well as a third one not mentioned by Cresswell: cost (elsewhere I have discussed other elements: see identifying references). Frictions refer to the hurdles scattered along our paths: the barriers that stop, impede, or inconvenience our movement. By motive Cresswell refers instead to the 'why' of mobility, that is, to the degrees of choice and compulsion that people have in moving. Cost refers to the amount of money spent in the process of being mobile.

By disentangling these elements of a particular mobility constellation, I contribute to the literature on mobilities (e.g. Adey 2009; Binnie et al. 2007; Urry 2007) as well as to the islandstudies literature (e.g. Baldacchino 2007b; Royle 2001). Given the relative lack of attention to ferries and to islands in the mobilities literature, my aim is to scrutinize how mobility constellations unfold in insular and coastal contexts in order to generate new empirical knowledge. My research also draws upon and contributes to broader social and cultural geographical interests in socio-technical assemblages (e.g. see Robbins and Marks 2009, Bissell 2009; Middleton 2010; Sheller 2007). I use the assemblage concept to extend and further clarify Cresswell's (2010) constellation concept. Furthermore, by disentangling the mobility constellations in which ferries, islanders, and coasters are entangled I reveal a type of assemblage — a meshwork assemblage (after Ingold 2007)—previously neglected within the assemblage geographies literature.

\section{Constellations as Assemblages}

In order to understand the historical lineage of particular constellations and to better comprehend how mobility is related to power and domination, Cresswell (2010) argues that we must focus on three dimensions of mobility constellations: sheer physical movement, representations of mobility, and the experiential practice of mobility. Disentangling the particular patterning of these three elements reveals that mobility is a differentially accessed and 
differentially distributed resource which is both productive of unequal social relations, and in turn produced by them. Cresswell's aim in generating the constellation concept is to facilitate the development of a meso-theoretical approach to the study of the politics of mobilities. My aim in this paper is to extend his conceptual development by further defining mobility constellations. To do so, I conceptualize a mobility constellation as a type of socio-technical assemblage. Simply put an assemblage, like a constellation, is a composition of things that are believed to fit together. Viewing mobility constellations as assemblages allows us to further understand the patterns of movement that constitute them as emergent, dialectical articulations of more-thanhuman actors occasioning variable degrees of connection and disconnection (Middleton 2010). 'More-than-human' assemblages recently have been examined amidst places, animals, humans, and material objects (e.g. Adey 2010; Graham 2002; Law 2002; Middleton 2010; Sheller 2007). For example, in the context of mobility geographies, Sheller has examined how automobility shapes corporeal existence, spatialities, temporalities, and material environments by crafting the 'driving body as an assemblage of social practices, embodied dispositions, and physical affordances' (2007: 176). Similarly, Adey’s (2010) research has examined the assemblage of aeromobility especially in regard to affect, politics, and historical relations. Such studies stress a relational ontology between people and the inanimate world. These assemblages establish connections between technologies and people and more broadly between 'social representations and discourses, and subjective experiences, ideas, and emotions' (Robbins and Marks 2009: 179).

While Cresswell (2010) does not offer a typology of constellations or an organizing criterion that can be used to characterize different constellations, the literature on assemblage geographies provides us with four different forms of assemblages: symmetrical, intimate, 
metabolic, and genealogical (Robbins and Marks 2009). These are not exhaustive and mutually exclusive categories but rather tropes whose deployment allows for different explanatory approaches. While this is not the place to review in detail these four tropes, what I wish to do here is suggest a fifth one, which we might call a meshwork assemblage.

The idea of a meshwork comes from the work of Ingold (2007). For him a meshwork is an ensemble of wayfarers and their trails in the world. A meshwork is a pattern of interwoven traces left by people's movement - a pattern that reveals how lives are lived along the process of movement. Wayfarers do not move from stage to stage according to a precisely predetermined plan based on a network of intersecting destinations. Rather, wayfarers' mobility is emergent because it is negotiated along the way, due to an open-ended and fluid disposition toward movement. Wayfarers' movement 'orientation and pace' is 'continually responsive to [their] perceptual monitoring of the environment that is revealed along the way,' writes Ingold (2007: 78). The wayfarer 'watches, and listens and feels as he [sic] goes, his entire being alert to the countless cues that, at every moment, prompt the slightest adjustments to his bearing' (2007:78). A meshwork is not a network. A network is an assemblage of disconnected dots waiting to be connected - a web of lines prepared in advance for a traveler so she may move linearly from A to B with a sense of uncaring disconnect toward the places in between.

I argue that the different natures of a meshwork and a network greatly reside in their differing affects. Affect in this particular case refers to the pre-objective emotional and sensorial dispositions of people's movements, and to what these dispositions reveal about the relations between people and their environments. Affect binds together people and their places (see Woodward and Lea 2009), coloring more-than-human movement, the experiential practice of that movement, and the discourses informing it. Affect animates mobility constellations and 
assemblages, distinguishing them from one another. Studying affect as the force animating a particular mobility constellation or assemblage shows us how the nexus of the social and the material intersect, and how those intersections are lived and practiced by the continuous doings of their actors.

Merging the study of islands' social and cultural geographies with Cresswell's (2010) approach and with the assemblage concept can allow us to better understand the power dynamics at play on the $\mathrm{BC}$ coast. Island studies literature shows rather clearly that the trails islanders weave constitute deeply conflicted choreographies (e.g. Baldacchino 2007c). Baldacchino (2007d) explains that islanders worldwide are suspicious of (if not outright opposed to) technologies affording connection, and yet they are not immune to the seductive pressures and promises of connecting to the outer world (also see Cosgrove 2007; Hunter and Corbin 2007; Källgård 2007). Fixed links (or at least predictably moving ones like scheduled ferry service) allow islands to become part of greater wholes: of socio-technical assemblages that deeply transform them - for better or for worse (Knowles 2000).

Upon close ethnographic look, disconnection and connection sensibilities writ large certainly do shape mobility constellations of the $\mathrm{BC}$ archipelago, but rather than (dis)connection per se it is (in)convenience - a subset of the broader issue - around which struggles emerge and contradictions unfold. Sheer disconnection, indeed, cannot be the issue for islanders who have chosen to move to (or chosen to remain in) places served by regular boat service. Indeed, the matter is not whether islands should be accessible, but in what ways they are and should be. This is inevitably a matter of perspective: to be too convenient to be reached is a problem for some, and conversely for many others access is currently not convenient enough. I now turn to these 
ethnographic dynamics, interpreting (in)convenience as the affective nexus of political struggles over island and coastal mobilities.

\section{Method}

I draw my data from a larger 'mobile ethnography' (Büscher and Urry 2009; Watts 2008; Watts and Urry 2008) conducted in coastal BC between 2006 and 2010. Beside a focus on mobility constellations the research examined how mobilities are performed in day-to-day life, focusing in particular on the performative transformation of time and place, as well as the nature of the interaction between ferry users and boats. Mobile fieldwork entailed travel to, on, and from ferry boats, for a total of about 250 journeys, and about 400 ethnographic interviews conducted with a diverse sample of island and coastal residents, and some tourists. Data analysis entailed drawing out broad themes that emerged from the data and developing key, narrower themes-following basic principles of phenomenological inquiry. Every informant gave informed consent to participate and agreed to have their identity protected through the use of fictitious names. More information on the methodological procedures of this research can be found in (identifying reference).

With the exception of the largest island - Vancouver Island, which hosts a population in excess of 700,000 - almost all of these coastal and island communities are inhabited by 5000 residents or less. An extensive network of ferry boats owned and operated by British Columbia Ferry Services (hereon: BCFS) provides access to all these communities. A de facto private corporation, BCFS conducts operation in 47 ports of call situated on 22 islands and eight ports on the $\mathrm{BC}$ mainland through a multitude of routes ranging from ten minutes to 36 hours in sailing length. Because there are no fixed links in the region, these boats are lifelines of great relevance to all locals. 


$$
\text { -- Insert Map } 1 \text { about here -- }
$$

Map 1: The BCFS network of routes. Reproduced with permission. All rights reserved.

\section{The Politics of (In)convenience}

A central theme to emerge from this ethnography is that almost none of the islanders and coasters I interviewed desire a complete disconnection or, conversely, the kind of connection that might be provided by a fixed link. Their key affective disposition to their ferry mobilities is instead one of (in)convenience. The word 'convenience' refers to ease, comfort, suitability and affordability for purpose. Interestingly, it derives from the verb 'to convene,' which refers to the coming together of a body. In this context convenience is a relational 'embodied sensibility' (Bissell 2008; Sheller 2007: 179) emerging from the circulations, ways of making place, and actions performed by ferries, riders, routes, and route owners. Convenience circulates between bodies and object, between islanders and ferries. As ferries convene in places, affective economies of convenience emerge - convening in some places, at some time, and for some people but inconveniencing others.

Different entanglements of physical movements, of mobility practices and experiences, and of discursive representations have different histories and geographies (Cresswell 2010). A brief analysis of the historical geographies of ferry mobilities of the BC Coast reveals the evolution of the meanings and consequences of (in)convenience. For the better part of the twentieth century the sea routes that BC Ferries travel had been legally entrenched as 'commons' (for a recent elaboration of this concept see Howitt and Hillman 2009): spaces whose navigation was intended as an extension of the civic right to free movement. The routes were designated as 'public marine highways' and the ferries that provided public transport were publicly subsidized, 
allowing for travel at substantially reduced prices than market forces alone would have determined.

But over the last seven years, BCFS in alliance with the provincial government of BC have pushed for a new mobility constellation founded on slightly modified principles of user pay and in de facto privatization (for an overview of related transport processes which entail the shifting from government to governance see Knowles 2004; Shaw 2000; Shaw, Knowles, and Docherty 2008). The establishment of semi-privatized transport routes and the growing dependency on those routes by islanders and coasters have resulted in making travel unevenly (in)convenient.

Mobilities are differentially accessed resources (Bissell 2009; Cresswell 2010). It follows that mobilities are differentially convenient too. For instance for Jerry, who travels from Victoria to Vancouver mostly for business meetings, seaplane service between the two cities' downtown cores is more convenient than ferry service between the ports of Swartz Bay (Victoria) and Tsawwassen (Vancouver). 'However,' he hastens to add, 'the ferry is very convenient when I want to drive to Whistler for a weekend getaway.' Ferry service to Salt Spring Island is equally convenient for Tom and Mandy, who reside part time on that island: 'We're not in a hurry when we come over to the island because it's our getaway for a week or two,' she says to me, 'we just plan around the ferry schedule.' While ferries seem rather convenient for those who do not need them regularly, for most year-round residents of small islands and coastal towns, ferry mobilities feel rather inconvenient. The village of Alert Bay represents in many ways a perfect microcosm of the BC Coast's affective dispositions towards mobilities.

Alert Bay lies on Cormorant Island, in the Broughton Archipelago—off the north eastern corner of Vancouver Island. The island is the home of the Namgis First Nation-though the 
Namgis do not consider themselves 'rooted' here in any inalienable way, since they came from the Nimpkish Lake area of Vancouver Island. Alert Bay is a small village of about 600 people who are members of the Namgis aboriginal First Nation. Another 600 people or so live off the reserve land, in the houses south of the village. The island is small-about $4 \mathrm{~km}$ long and $1 \mathrm{~km}$ wide at its largest point. Aside from very limited commercial fishing there is no sizeable economic production of any kind on the island.

Until the early 1990s Alert Bay served as a convenient mooring on the pathways of fishing folks. Roads on northern Vancouver Island were unpaved and automobiles and trucks, therefore, were of limited use. Fishing craft and other sea vessels navigating between the south and north coast would regularly call at Alert Bay for rest, refuel, repair, and trade. Alert Bay was then 'the capital of the Broughton and the north [Vancouver] Island'-as several informants explained to me with a tone of pride in their words - and therefore a truly important node in the local web of intersecting marine trails. But as the fishing industry declined, and as northern Vancouver Island roads became paved, Alert Bay gradually lost importance. Very few people now use their own boat to travel up and down the coast or eastward to places like Village Island and Echo Bay. Most people rely instead on their cars and the BCFS service westward to Vancouver Island. No ferry service exists to the rest of the Broughton, or north to the Queen Charlotte Sound, or south to Desolation Sound. In a telling sign of their decline, the names of these locations and the sea routes binding them are left off the BC Ferries map shown above.

As we stroll on a rocky beach not too far from the ferry terminal, a local informant, James, and I stop to look at a friend of his as he carves a canoe. 'Canoes are like ferry boats in a way,' he tells me, 'we use them to be in touch with the rest of the world and to leave the rest of the world behind.' James is of mixed descent: aboriginal mother and English father. He is a well 
educated man with a good sense of local history. He shares with me his reflections on the changing historical identity of Alert Bay. And like others on this island he tells me that it makes no sense that, amongst other inconveniences, their ferry route has to hug the Vancouver Island coastline for about 40 minutes before reaching the terminal at Port McNeill. The nearest spot on Vancouver Island where the ferry could dock if a terminal were there is about ten minutes away. But to save on the costs of operating a second boat and building another terminal Cormorant Island and its northern neighbour, the town of Sointula on Malcolm Island, share a vessel—the Quadra Queen II —and a docking facility on Vancouver Island. James observes:

So, not only do we pay higher fares for the extra fuel we need to get to Port McNeill, but we periodically get into conflict with the folks on Malcolm Island because we have different priorities and needs, so none of us here is saying 'build a bridge,' or, you know, 'take your ferry service away and because we want to be alone.' We just want more respect for our needs. These waters have been around for a long time, and people have been riding canoes on them for a long time in all directions in the Broughton, so what we have here now makes very little sense historically, you see what I mean?

'I think I do,' I tell James. 'Do you think life on the island would be different if riding that ferry would be free, though?' I ask.

'Well, yeah, there is no doubt about it,' James answers without hesitation. He continues:

But I'm not sure it would make all the difference in the world. Could more people on this island commute to jobs on Vancouver Island? Maybe, but you wouldn't see an immediate 
reduction in unemployment, you know. There aren't that many jobs in northern Vancouver Island, and there are even fewer people from Alert Bay trying to get them. Neither the First Nations nor the rest of the people on the island are your typical commuters. Take my neighbour: he moved away from Calgary because he was done with traffic and with the commuting lifestyle. And you'd see that back in the day either, you know, with the First Nation people. It was never a daily movement from A to B. People would go with the movement of the fish and the seasons, or would travel for ceremonies, for trade, for war, or to settle into a new place, or what-have-you. It's always been part of who we are here on this island and throughout the Broughton. Whether First Nations or European, I heard somebody say once, the people who live on an island don't travel to live, they live to travel.

James's distinction between people who travel to live and people who live to travel epitomizes the politics of island mobilities. Travelling to live is a way of organizing one's livelihood around the affordances of access-oriented transport. An islander who travels in order to live treats her island as a bedroom. For her the ocean is a segmented line made of little dots and dashes waiting to be connected-just like in the BCFS map. As de Certeau (1984; also see Ingold 2007) would have it, this automaton-commuter-like affective disposition to inscribing one's presence in space is in deep contrast to the practice of journeying as wayfaring. Wayfaring is a way of taking the line for a walk, a way in which movement tells tales—according to de Certeau (1984) and Ingold (2007). Living to travel means weaving together selfhood, community, and place through movement and narrative - it means wandering and wondering simultaneously, as opposed to merely transiting and transitioning between access points. 
Whereas the newer transport assemblage created by BCFS was planned to maximize convenience, its operation has resulted in unplanned and undesirable consequences. These consequences are the result of the struggle for dominance between BCFS' network-type transport assemblage and the more traditional meshwork assemblage of the $\mathrm{BC}$ coast. To further understand the struggle between these two assemblages and the related controversies over the meanings and consequences of convenience and inconvenience, we must first understand wayfaring in greater depth, and further juxtapose it to transport.

\section{Disentangling Wayfaring and Transport, and Uncovering a Meshwork Assemblage}

BCFS routes form a basic network of connections from location to location affected by a modernist planner's logic. BCFS confronts the aerial representation of the BC coast 'much as the colonial conqueror confronts the surface of the earth, or the urban planner confronts a wasteland, in preparation for the superimposition upon it of a construction of [their] own making' (Ingold 2007: 13). Thus myriad islands and coastal villages are cast in a space of supposedly 'convenient' access points. The network is signified by an assemblage of lines connecting A with $\mathrm{B}$ - while inevitably disconnecting both $\mathrm{A}$ and $\mathrm{B}$ from a forgotten $\mathrm{C}$ - and 'cast within a particularly abstract spatial and temporal typology' (Adey 2006: 344). This assemblage re-makes the $\mathrm{BC}$ archipelago by reclaiming ownership of public marine routes and therefore effectively positioning the transport service provider as land/ocean/lord.

Connections in this assemblage are made through the principle of time-waste reduction. 'In the past a captain would have a relaxed approach to sailing,' in the words of a Salt Spring Islander, 'sometimes he'd see you arrive late at the dock as the boat was sailing off, and he'd turn around to come back to pick you up.' But this affective disposition to ocean mobility as wandering has changed now. BCFS routes, like all routes typical of modern transport networks, 
function 'from point to point, in sequence, as quickly as possible, and in principle in no time at all' (Ingold 2007: 73) with little regard to the unique temporalities and spatialities of the places involved. This is an abstract approach which cuts islanders and coasters off from their wayfaring affects. Current BCFS routes are chain-like static geometric assemblages unconcerned with the local wayfaring meanings of movement.

'Point-to-point connectors' (Ingold 2007: 75) of this kind are completed, fixed objects that neither grow nor develop in harmony with the places they link. They are assembly-chainlike in nature, based on principles of fragmentation, instrumental orientation, and centralized planning. BCFS' routes treat seas as empty spaces to be filled with capitalist ventures. For BCFS oceans are spaces to move across, and problems to solve, not places of their own. Thus their routes become sailings across emptied space, connecting islands and coastal villages to larger towns and cities in a linear fashion, fostering a type of atomized, intermittent, and dependent movement that turns waterways into capitalist 'movement spaces' (Thrift 2008) and that transforms places scattered along waterways as degrees of problematic distance from urban concentrations. This assemblage is built on what Ingold (2007) would call a transport model.

In contrast, as James's observations show us, the assemblage of year-round islanders have shown many of the characteristics of what Ingold (2007) would call a wayfaring model. For further understanding, take for example Mike and Summer. Mike's family comes from Gilford Island, a traditional First Nation territory situated in the Broughton Archipelago. Mike, however, was born on Kingcome Inlet: a remote mainland village where his family travelled regularly. Life on Gilford Island and Kingcome Inlet proved to be unsustainable for Mike's parents, who decided to move to the village of Alert Bay when he was little. Mike inherited his fishing skills from his father, and worked as a commercial fisherman for most of his life - travelling 
seasonally as far north as Prince Rupert. Now Mike no longer fishes: the fish stock has been gravely depleted, salmon farms have wreaked havoc on local marine ecologies, and fishing is no longer a viable trade for him. Instead he carves cedar and sells his art throughout the region. In the warm season, much to his chagrin, he also finds part-time employment generated by the tourism industry.

Summer arrived on Vancouver Island in her early twenties after much traveling. Tired of being still she soon left for Salt Spring Island, where she built herself a cabin in the woods and lived off the land. Soon, Summer felt that Salt Spring Island was becoming too developed and decided to embark on a long hitch-hiking (part by car, part by boat) trip. She eventually stumbled upon Alert Bay, where she fell in love with Mike and the unique intercultural mix of First Nations and European cultures of the place.

Mike and Summer epitomize the affect typical of wayfaring still existent within this assemblage. Their lives are drawn through movement, by the will and the necessity to go where the currents take them, as it were. As islanders, their life paths are very typical as well. Islands are known to attract drifters: people who wish to begin life anew, often far away from whence they come (Royle 2001). The social landscapes of islands and remote ferry-dependent coastal villages of Canada's west coast are especially rich with drifters, seduced by the promises of alternative lifestyles. For many of these individuals movement is quintessential to personal and collective identity, their travelling is a way of being and becoming. Their lives and places are a meshwork of interweaving lines (Ingold 2007: 75): dynamic, unpredictable, with no clear roots and no obvious ends or boundaries in sight. Like Mike's and Summer's many islanders and coasters' lives plots are intersections of complex histories of places that continue to thread their 
way along the coast, open to being on the move, ready to rest in a temporarily beloved place while waiting to trace new trails.

Over the last decade the affect typical of the BCFS transport assemblage has transformed the earlier wayfaring mobility constellation 'restructuring and rescaling the very spatiotemporal fabric' (Sheller 2007: 178) of the BC coast. These reconfigurations in the mundane mobilities of islanders and coasters have resulted in the formation of 'cracks' (Ingold 2007) in this vast archipelagic assemblage. Cracks are accidental, unplanned problems in movement patterns 'caused by stress, collision, and wear and tear' (Ingold, 2007: 45). These cracks highlight the power dynamics of an assemblage divided by internal affective tensions. Losses in population diversity, a diffused sense of exclusion and dependency, and a reduced sense of freedom of movement are some of the ways in which these cracks manifest themselves in the lives and mobilities of many year-round island residents.

BCFS's vision of the sea as a problem, as a frontier to conquer, and a hurdle to cross, is the source of these cracks. Their assemblage is influenced by a distant and mainland-centric view of islands as aberrations from the norm. By pitting the sea as 'the most effective barrier' (Carlquist 1965: 4) to efficient transport the assemblage imposed by BCFS and the BC provincial government is resulting in the generation of multiple inconveniences. Borrowing from Cresswell (2010) and Cass, Shove, and Urry (2005), the re-definition of wayfaring mobility constellations unfolding through these physical (e.g. existence of barriers), organizational (e.g. the re-shaping of individuals' travel motives), and financial (e.g. rise in costs) forces are resulting in redefining the coast's earlier ways of life, replacing paths of traditional wayfaring with the routes of transport. Routes such as these are 'lines of occupation' dividing, disconnecting, 'cutting the 
occupied surface into territorial blocks' restricting rather than facilitating mobility, disrupting rather than servicing the places they occupy (Ingold 2007: 81).

'Transport,' Ingold (2007:78) writes, is characterized 'by the dissolution of the intimate bond that, in wayfaring, couples locomotion and perception.' 'The transported traveler,' he continues, 'becomes a passenger, who does not himself move but is rather moved from place to place.' New 'premium' (Graham 2002) routes featuring services such as private first class lounges, massages, and wireless internet access are the epitome of this affective orientation. On them the transported passenger is meant to skim, if not skip entirely, the surface of the ocean (after Ingold 2007: 79; also see Jensen 2004). This new transport assemblage presupposes that the value of convenience lies in obliterating the seascapes it crosses — or at best in using them as a visual backdrop for tourism promotion - and in transforming the communities it links as placeless spaces removed of their insular distinctions. In contrast, a wayfaring-based meshwork assemblage would (re)center upon inhabiting place; that is, not upon 'taking one's place in a world that has been prepared in advance for the populations that arrive to reside there' (Ingold 2007: 81), but rather upon practices, meanings, and experiences of participation, belonging, cooperation, and involvement of the coast's coming into its own being, without a final destination, through the interweaving of its paths and close-knit textures.

A transport assemblage marginalizes islands and coastal villages. On the other hand, a wayfaring-based meshwork assemblage can (re)transform BC's islands and coastal villages from their current position as bothersome dots on a map, back into their position as 'commons' (Howitt and Hillman 2009). Whereas government officials and BCFS officers intend to crisscross the coast with their gentrifying ambition, wayfarers in charge of their own meshwork 
assemblage could have the power to foster development of their communities and ways of life along the ocean, rather than across it and in spite of it.

A basic, practical way to achieve that would be to take back possession of marine highways as commons, to turn the ferry service into a user co-operative governed locally by the different communities and focused on the long term sustainability needs of year-round inhabitants, and to abandon the pay-per-use model with fares calculated on the basis of distance. A wayfaring mobility meshwork assemblage that is based on abandoning land-based and landbiased (Baldacchino 2007a) perspectives, and embracing a view of the world as a sea of islands (Hau'ofa 1994) would (re-)create the sea as meshwork of interwoven paths along which places are dwelled in — not merely built upon — and borne out of movement — not merely (dis-) connected (Ingold 2007).

\section{Experiencing and Practicing (In)convenience}

As Cresswell (2010) explains, aspects of mobility constellations such as friction and motives allow us to dissect the unequal power dynamics shaping the patterning of sheer physical movement, representations of mobility, and its experiential practice. In the ethnographic case at hand frictions, motives, costs and their consequences reveal in precise details the unfolding of the politics of (in)convenience and highlight how the struggle between a dominant transport assemblage and a dominated meshwork assemblage is felt and enacted in islanders' and coasters' everyday life.

\section{Frictions}

Mundane technologies mediate experiences of place and movement in deeply meaningful ways (Michael 2000). They are part of assemblages of human-objects-environments that may enable or restrict an individual's coordination of day-to-day mobile tasks (Middleton 2010). 
Restrictions of movement are what we may call frictions, following Cresswell (2010). Cresswell utilizes a variety of examples to explain that frictions are the forces that stop mobilities, but he never clearly defines the term. Extrapolating from his argument and extending it we may say that frictions refer to the ways in which assemblages restrict mobility by impeding or inconveniencing sheer physical movement and aspects of its experience.

The existence of frictions highlights some of the most mundane inconveniences caused by the BCFS transport assemblage. But despite their deeply banal relevance, the value of these inconveniences points to a very important dimension of the struggle between a transport model and a wayfaring model. Whereas BCFS' transport orientation allows the corporation to view frictions as simple problems of inefficiency to be solved through a reactive customer service approach, the affective orientation of islanders and coasters prompts them to view frictions as indisputable evidence that the governance of the current ferry assemblage is inherently discriminatory, and that the frictions it generates could only be solved by a radical rethinking of its existence and of the collective identity of its users. In the succinct words of an informant, 'we are not customers whining for a better service from a private operator; we are citizens with the Crown-given right to be treated equally.' And in the words of another informant: 'like air and land movement, sea movement has allowed for the formation of this country. To say that marine highways are a privilege and they are different from air routes or land-based highways is an insidious way of making us second-class citizens and paying disrespect to the history of this region.'

The mundane frictions that inconvenience islanders and coasters may take the simple form of poor travel experiences such as sea-sickness and long waits. For example, travel to Haida Gwaii, the central coast, upper Sunshine Coast, or the Northern Gulf Islands is very often 
disrupted by high winds that cause swells, delays, and cancellations. In spite of the region's climate, BCFS in 2007 purchased a new ship with a relatively flat hull which causes instability and consequently sea-sickness. 'And that's when winter trips home started smelling like vomit,' an upset Graham islander tells me. Even nice days require careful planning, as they attract much tourist traffic. A ship's size cannot change with the seasons, and since no additional vessels can be called upon due to costs, there are often long boarding line-ups. Regrettably, BCFS refuses to allow reservations in most areas of service, and in many cases simply utilizes road shoulders to line up traffic, causing people to put up with the heat (or the cold during peak winter travel dates) in their cars and to rely on nearby bushes (or demanding far walks) for public washrooms. These inconveniences offend the dignity of islanders and coasters and contribute to building the image of BCFS as an uncaring, disrespectful outsider which refuses to recognize its essential function.

A transport assemblage imposes its abstract temporalities on the places it serves. Trains, for example, have played a critical role in the implementation of uniform time zones. Similarly, ferries operate on principles of clock time. But islands and coastal towns have a radically different disposition towards time — which is less linear and formal and more emergent and relational (see identifying reference). Whereas a meshwork assemblage built around the unique local dispositions towards temporality could be sympathetic to local needs, the central planning typical of a transport assemblage causes sharp inconveniences. Morning departure times, for example, are crucial for islanders needing to commute off-island for work. Yet, in places like Sointula the first departure is no earlier than 7:50am, and in other places as well departure times fail to serve islanders' needs by not synchronizing with bus schedules, or by forcing people to travel overnight instead of during the day time. 
Transport assemblages are built on principles of user-pay differential access. As Crang (2002) writes, the privileged mobilities of some always expose the frictions endured by others. So, whereas massages, buffet meals, free wireless internet, exclusive quiet rooms, and movie lounges are available for the 'kinetic elite' (Graham and Marvin 2001) of the BC coast on the big new ferries like the Coastal Renaissance, floor-sleeping, no food (or dismal vending machine food at best), metal chairs, loud engines, and dungeon-like lounges are featured as 'amenities' on the smaller, ageing vessels. In fact, whereas the meshwork assemblage of the past recognized accessibility as a right equal for all, the current transport network views the unprofitability of a route as a justification for poor service or even outright service discontinuation.

Frictions also expose the fact that those who suffer from inconveniences the most are those whose stories and movements have been traditionally marginalized and controlled. In fact, over the years BCFS has been accused by islanders and coasters of discriminating against aboriginals, differently-abled individuals, and small, remote communities. For instance, BCFS's policy of charging heavily for extra luggage means that groceries and other essential goods end up costing dearly for walk-on passengers to Klemtu and Bella Bella—both very remote aboriginal communities. On many ships, differently-abled passengers have to cope with very inaccessible washrooms and passenger lounges, steep stairways, and the absence of elevators. Small community residents also complain about BCFS's lack of involvement in local community events. In contrast, BCFS is seen as much more accommodating of tourists' whims and desires; some boats slow down and even take detours to allow tourists to take good pictures of whales (while locals just need to get home or to stores in time), and the corporation's marketing unduly exoticizes the coast—making some residents 'feel like zoo animals' in an informant's words. 
Because a transport assemblage is explicitly built on principles of central planning and control, it is not unreasonable for islanders and coasters to feel marginalized and unheard. For example BCFS has created local advisory committees, but according to many of their members these tend to work as 'shallow forms of window-dressing,' 'smoke in the government's eyes,' and 'glorified focus groups' with almost no power at all. As a private corporation whose extravagantly paid executive leaders are basically unaccountable to the public, BCFS enjoys great degrees of discretionary freedom, deeply angering its customers. Islanders and coasters' anger is exacerbated by lack of public concern. 'Mainlanders don't understand the seriousness of our problems,' tells me Jenna, a Quadra islander 'and every time they hear about our complaints they tell us to suck it up because we moved here. Yeah, I moved here, in 1989, when the road to my island was public. So, no, I didn't choose to have a private corporation control access to my home.' Like Jenna, hundreds of the islanders and coasters I interviewed feel 'forgotten,' 'neglected,' 'silenced,' 'marginalized,' and 'misunderstood' by an urban provincial majority who views their mobility constellation as a free 'cultural choice' (Kabachnik 2009). This 'culture as choice' (Kabachnik 2009) discourse is then utilized to dismiss their complaints. And yet, the current transport assemblage was never a choice for the wayfaring public of the BC Coast-it was simply imposed on them without their consent and consultation.

Locals' accusations of disrespect, carelessness, racism, able-ism, and cosmopolitanism paint a vivid picture of BCFS' transport assemblage as a foreign, inimical, immoral, and even unlawful model. The existence of these frictions is not accidental or easily remediable-locals say. The inconveniences that this assemblage is causing in the local ecology exist because the current transport constellation shows no respect for the traces previously drawn over ocean and coastal surfaces by a different, meshwork-like assemblage which treated everyone with equal 
respect. 'Every time we'd get on a boat some forty years ago,' many islanders have told me, 'everyone was treated as a gentleman and a lady, with access to silverware and staterooms for everyone.' A day of travel, before the current model emerged, was 'a story in itself, something to remember, something to tell home about,' in the words of an informant, 'now you just have to suck it up, shut up, and let them control your every move.'

\section{Motives}

'Why does a person or thing move?' asks Cresswell (2010: 22). The differences between choosing and being compelled to move are never clear or pure, Cresswell argues. But whether it is an external cause or an internal reason, or overlapping shades of both, motives play an important role in constellations of mobility as they highlight the consequences, functions, and meanings imputed to movement. Mobility motives are also always shaped by degrees of intensity — this is why beside motives themselves we must consider their 'force' (Cresswell 2010: 17). Motives are therefore definable as the scopes and objectives underlying mobilities, with their force indicating the strength of such scopes and objectives. It follows that to understand why islanders and coasters use the ferries requires not only that we examine the motives for their travel, but also the intensity of these reasons.

Travel frequency reveals quite clearly why islanders and coasters move and how dependent they are on their ferries. Residents of smaller communities (e.g. Southern and Northern Gulf Islands) that are near small and large cities can generally find basic goods without having to leave their places, but higher order goods can only be gotten through travel off island. A few of these islands and coastal villages have no doctors, police or government presence, clothing stores, banks, restaurants, car mechanics, and extremely limited employment, only partial schooling (or none at all) and no locally produced foods. Residents must depend on the 
larger places to which ferries connect them. Travel in all these communities is frequent (ranging from five times a week to once a week or twice a month for most people).

In more remote settlements people either try to do with little or to do without, or they may rely on mail catalogues, shipping services, and bartering or co-operation. Once, twice, three, or four times a year tends to be the ferry travel frequency there. These journeys tend to be about one week long and filled with chores and errands, often coupled with family visits. The affective pull of ferries is lesser on larger towns and cities on Vancouver Island, which have nearby almost everything that small cities have to offer. There, ferry travel is not very frequent (typically no more than once a month for most people).

Travel motives and motive forces are very important because they reveal the affective pulls and pushes through which islanders and coasters bind to and separate themselves from larger islands and mainlands, and which therefore enable or limit their self-sufficiency and their reliance on the BCFS assemblage. Differing travel motives and motive forces also reveal that what may be considered convenient access by some, may be considered inconvenient by others. Because of the insight that it provides us into their affects, understanding islanders' and coasters' motives also reveals the potential for a certain type of constellation or assemblage to be successfully functional. A transport assemblage requires for its efficient operation the existence of a passenger who travels to live. On the other hand, a meshwork assemblage works best for a constituency of people who live to travel. In those cases where a transport assemblage is designed to serve the motives of the latter type of people, inconveniences and all sorts of cracks in the system would logically seem to arise. Such is the case on the BC Coast.

One of these cracks in the system is constituted by access that is too convenient. Ease in accessibility is a key characteristic of a transport model. But this is a problem for people who 
view much too convenient access as a threat to self-sufficiency. Rick, a Denman islander, explains:

Denman is ten minutes away from Vancouver Island. In about half an hour I can be at a large strip mall in Nanaimo or Courtenay. And unfortunately I often am. And so are my neighbors. And that kills all business on Denman. You can't build a house and leave large gaping holes in the walls and foundations; it will crumble. The same goes with an island: you can't have a strong island economy if everyone depends on the economy of an outside community for everything.

Many islanders' motives for riding the ferries connote a certain pride with being a responsible environmental citizen and community member. For Rick it is a way of reestablishing a relationship with place, environment, and community at a local level, and the inconveniences that limited ferry service would embody are key to 'the creation of a safer, less polluted, friendlier localit[y]' (Aldred 2010: 35). Like Rick, many small islanders are the antinomy of self-indulgent consumers. They loathe mass culture, large industries and commercial development, and most do not desire 'twenty-five brands of everything in five different shops to choose from,' in the words of Emily. But, the transport assemblage of BCFS tends to 'pull' some islanders and coasters too intensely, failing to respect the cultural uniqueness of a meshwork where relatively unrestricted movement has historically meant that no location exerted an overly dominant pull over all others.

Differences in terms of travel motive forces - with some destinations voicing the need for less service and others voicing the need for more — can be difficult to manage by a centralized 
managerial model that demonstrates both inability and unwillingness to listen. Further complicating these complex geographies of (in)convenience are diverse social relations and identities which the current transport assemblage ignores. Different motives and motive forces, for instance, are common amongst part-time and full-time residents (for parallel findings see Connell and King 1999). Whereas full-time residents find themselves travelling to meet life's basic demands, part-time residents tend to view ferry travel as the means to leisurely getaways.

The existence of different users with different motives in itself is really not a problem, but the problems arise in relation to motive-cost configurations. A user-pay, profit driven transport assemblage works best when people's travel motive force is uniformly high. Indeed, the more frequently all riders travel — for whatever reason - the more money the transport providers make and the more money they are able to reinvest in the system. In light of this a transport assemblage does not provide differential service according to different motives or different identities of users; a fare is the same whether a full-time islander is travelling to buy fresh produce, or a part-time islander is travelling to one's island getaway to enjoy a weekend of sailing and relaxation. In other words, a transport assemblage is unconcerned with the stories and identities underlying people's movement.

On the other hand, a meshwork assemblage is unthinkable outside of the stories, identities, and motives pulling and pushing people to move. In practice, a meshwork assemblage should be respectful of islanders' desire to be relatively self-sufficient and understanding of their basic needs of access. A meshwork assemblage therefore works best when people's travel motive force is low, though not nil. A meshwork assemblage that does not depend on revenue for its continued existence could continue to survive without the need to stimulate people to travel. In this sense, instead of investing in making ferries prettier and more plush, public re-investment in 
the system could go towards making local ways of life and economies more sustainable and less dependent on fossil fuels. A meshwork assemblage shaped to encourage sustainable mobilities would also rely less on inciting non-full-time residents — such as part-timers and tourists— to travel.

The consequences of inciting anyone to travel in order to meet the bottom line, without taking into account the long term costs of the operation of this type of assemblage, have now begun to manifest themselves in deep ecological cracks in the system. For example, anyone can buy property on the BC Coast. Buying land away from where one obtains an income puts significant pressure on the local real estate market, and many full-time residents deeply resent this. Judy, a Hornby islander, explains:

The moment the rainy season ends all the part-timers show up. Our island doubles in population. Everyone gets off the ferry, drives to their cabin, soaks in the sun, and then goes back home after Labor Day. But guess what? I live and work here year-round, but I can't buy a home on my island because I don't nearly make as much money as Joe Calgary and Jane California do with their big city jobs. I can pay max $\$ 150,000$ for what I would call a home, but they can pay $\$ 400,000$ for what they call a small cabin.

Real estate speculation has driven property value up over the last few years, with prices multiplying fivefold in some communities (for related findings see Clark et al. 2007). This has squeezed many small full-time islanders off the market, since on-island employment is limited and far less rewarded than off-island work. Even those who owned a home before the real estate boom, of course, need to pay much higher property taxes and suffer the consequences of 
speculation. Renting one's second home while one is away at a fair price would seem like a partial solution, but as Kerry explains:

The moment the landlord shows up at the ferry at Horseshoe Bay is the very same moment the low-income rent-paying Bowen Islander is faced with two choices. Choice 'A:' catch the ferry off island for the time the landlord is on the island and find something to do in Vancouver for two months-because obviously he's not going to find any housing on Bowen for the summer months. Or choice 'B:' pitch a tent in the bushes till the landlord goes back home. Choice 'B' sounds like fun, but it isn't. One night my fouryear old daughter told me she couldn't go to sleep in her sleeping bag without one of her favorite stuffed animals and I had to explain to her that it was in storage till the fall. Can you imagine what that feels like?

The present consequences of the motives for which people rely on the ferries, and the force of these motives, are of key importance for the future of the BC Coast. A transport provider can remain largely unconcerned with the broader politics of place-making. Whether it is full-time islanders, part-time islanders, or tourists riding the ferries does not matter to a corporation whose mission is apolitical. All that matters for BCFS is the profitability of routes. On the other hand a meshwork assemblage characterized by local governance and lack of concern with profitability could make strategic political choices to encourage certain travel motives and discourage others - all the while reducing islands' and coastal towns' dependence on larger centres.

For example, as an informant suggests, 'ferry fares could be deductible off income taxes according to specific criteria driven by the need to encourage certain people, like young families, 
to live on islands.' Conversely, as another islander argues, 'fares could be calculated on the basis of how dependent on larger centres some communities are, with more dependent communities receiving larger breaks on fares. Then, the government, through a long-term strategy could invest more greatly on the economy of these communities to help them become more self-sufficient.' But when a transport assemblage is kept at arms' length from policy-makers it becomes impossible to adjust the rationale, direction, and the intensity of mobility. Transport remains inflexible and unresponsive to the lessons learned along the pathways of movement. Costs

Costs of travel are at the core of assemblages, affecting different people in different ways. There are of course different kinds of costs encountered in the process of being mobile. The most obvious cost is represented by immediate expenditures such as the payment of a fare in the case of public transportation. Then there are less immediate costs, such as tax-based payments towards the building and maintenance of infrastructures. And finally there are indirect costs, such as the price each of us pays for how meanings are differentially assigned to certain mobility practices (e.g. fossil fuel-consuming mobilities vs. carbon emission-free or renewable fuelconsuming mobilities) and the mobilities of some people (e.g. tourists benefiting from an infrastructural development vs. locals suffering from an unsustainable local economy). Disentangling mobility constellations should shed light on the meanings and consequences of all these types of costs, and on how these costs influence and intersect with one another.

At the more immediate and obvious level, today's ferry fares are far from the nominal fees they used to be. For example, today a car and driver pay CAD $\$ 59.50$ (one way) to cross from Vancouver (Tsawwassen) to Vancouver Island (Swartz Bay-Victoria); \$53.80 (return) to do the double-crossing (through Denman Island) from Vancouver Island to Hornby Island; \$55.00 
(return) to cross from Vancouver (Horseshoe Bay) to the lower Sunshine Coast (Langdale); and $\$ 38.10$ (return) from Vancouver Island (Crofton) to Saltspring Island (Vesuvius). Fares are much higher for travel to and from the north and central coast. Travelling one way from Haida Gwaii to Vancouver Island (Port Hardy) will cost a car and a driver $\$ 824$ (one way) - inclusive of an $\$ 80$ fee for a cabin for the overnight trip to Prince Rupert. A round trip from Bella Bella to Vancouver Island (Port Hardy) costs instead $\$ 600$ for car and driver.

Higher fares have reduced the accessibility of many of these communities impairing possibilities for social inclusion and social justice (for a broader discussion of these dynamics see Farrington and Farrington 2005; Hine 2007; Onmacht, Maksim, and Bergman 2009). Steep and rising ferry fares mean an increase in islands' and coastal communities' cost of living, given the limited elasticity of mobilities on islands and remote coastal villages (on related processes see Rajé 2007; Schönfelder 2007). Costs turn islanders and coasters into groups of 'differently mobile passengers' (Bissell 2009) with two related consequences in particular.

The first consequence is a rise in place exclusivity: the more expensive it is to reach a place, the more exclusive it becomes for those who can claim land ownership there. Some landowners (those who bought large properties in the 1990s before the real estate boom) and developers obviously view this as a positive fact, but others who suffer from the scars of unaffordable housing are negatively affected by this process. Bruno, a rent-payer resident of the Sunshine Coast, observes that 'fare increases turn places into gated communities, into playgrounds for the rich. And it works like a vicious cycle: the more fares increase, the more outside demand for exclusive real estate increases, and the wealthier residents are, the more the BC Ferries can feel free to raise fares.' 
The second consequence is a loss of population diversity. The more expensive it is to live on a ferry-dependent island or coastal town, the greater push will be exerted on those with modest incomes. In the words of Ed, 'young families like ours are the first to feel the pressure to move away. When I do leave, and sooner or later I might have to, the youngest guy on the volunteer fire fighter crew will be 54 years old.' Loss of population diversity affects everyone, regardless of income. Young families and their members fill important roles — from many volunteer positions to retail jobs and trades - and their out-migration is beginning to cripple communities' sustainability. Paula, for example, confesses:

I am afraid I am losing hope in the future of our island. The average age of our yearround residents is around 55. And it keeps going up. The elementary school has lost half its kids over the last four years, and real estate and ferry fares have almost tripled. We are at a point when long-time residents of our island now live on Vancouver Island and take the boat here in the morning. They take care of rich people's gardens and homes, they staff the stores where these people spend their money, prepare them food in restaurants and coffee shops, and then catch the ferry to go back off the island at night. Many of them then go on employment insurance in the winter. And their ferry fares keep going up.

BCFS' transport assemblage has raised prices in uneven ways. Fares on the main routes connecting the larger population centres of Vancouver Island with the mainland have not increased as much as minor route fares. The former routes, after all, are profitable and therefore fares do not need to increase as much. The principle that every route must be profitable and that those living on the periphery are 'unimportant, marginal, and negligible' (Avraham and First 
2006: 71) has meant that those who live farther and in smaller communities - and therefore who need to travel the most- have had to face greater cost increases. And this, in the words of Bruno, has created dangerous vicious cycles.

While few forces have tempered these cycles, their strength has not been significant enough. The manager of an island co-op grocery store explains:

With ferry fare increases we've seen more business volume. People shop locally more, and that is a good thing for everyone on the island. But I still need to import $99.9 \%$ of my stocks from off-island, and that means that the price of food is higher because the costs of shipping by ferry are higher. The only solution would be for more food to be grown on the island, but how many farmers are you going to find that are ready to pay a million dollars to buy a ten-acre property?

All of these consequences of rising costs can be understood, metaphorically, as ruptures in the surfaces of the BC archipelago. The lines weaved by BCFS routes are resulting in the displacement of older surfaces and in their replacement with linear edges cutting off islands from one another. These cracks are not accidental — they are instead the result of the application of assemblage forces that instead of running along with the preferred movements of islanders and coasters zigzag like lines of breakage. Borrowing from Ingold (2007: 45) cracks of this kind 'show no respect for the traces that may have been drawn over a surface' by years of meshworklike mobilities. These cracks are, of course, metaphorical, but so are the assemblages we have been examining — transport, meshwork, and the like. But no matter how metaphorical 'some kinds of ghostly lines, however, can have very real consequences for people's movements' 
(Ingold 2007: 49). Experiences of injustice, marginalization, and dependence- and all the costs associated with them - are certainly very real and empirically undeniable, and unmistakably point to a politics of mobility that is breaking away from meshwork-like models of the past and functioning without much care for the future either.

\section{Conclusion}

Throughout this paper I have extended Cresswell's (2010) important concept of mobility constellations. In more detail, I have further defined aspects of mobility constellations such as friction and motive, and I have introduced an aspect not examined by Cresswell: cost. Moreover, I have overlapped mobility constellations with the concept of assemblage (Robbins and Marks 2009). Because their basic definitions are synonymous - both being ensembles of objects organized together-I have found the simultaneous use of these concepts to be free of inconsistencies and to be a potentially fruitful way to bridge the assemblage geographies literature with the mobilities literature. Finally, in paying attention to the unique historical configurations of $\mathrm{BC}$ coastal mobilities I have traced the existence of an assemblage trope previously ignored within assemblage geographies, and one that remains much underutilized in the mobilities literature as well: the meshwork assemblage (after Ingold 2007, 2010).

My empirical findings have pointed to the existence of a conflict between the transport assemblage imposed by BCFS and the provincial government of $\mathrm{BC}$, and the meshwork assemblage typical of the wayfaring affect of islanders and coasters. This ongoing conflict between a dominant assemblage — typical of a modern transport network—and a dominated assemblage which refuses to subside is experienced by islanders and coasters through a series of inconveniences. Whereas some of these inconveniences result in disconnecting in favorable ways islands and remote coastal communities from larger islands and cities, other inconveniences have 
caused the emergence of cracks in the ecology of the region. These metaphorical, yet real, cracks threaten the sustainability of island and coastal life, jeopardizing in particular locals' wayfaring ways of life as well as their sense of free and autonomous movement and self-sufficiency, their identity as equal citizens, and their ability to sustain themselves economically.

These empirical findings inform in turn the conceptual and practical development of what I have called a meshwork assemblage. In part already existent—due to its entrenchment in historical mobility constellations - and in part a mere potential future manifestation of forms of affect and socio-technical relations currently latent within the local regional culture, a meshwork assemblage seems to offer all students of mobility much material for reflection and debate. Whereas transport mobility assemblages are controlled and restricted, a meshwork mobility constellation is 'free to go where it will, for movement's sake' and 'in its own time' (Ingold 2010: 73). Rather than moving from point to point, in a hurry, and in sequence, a meshwork assemblage is dynamic, organically growing, and self-adjusting. Rather than dismissive or ignorant of the stories behind people's movements, a meshwork assemblage is continually weaved together by inhabitants who take active part in the assemblage's changing and coming into being. This unique form of affect and assemblage are typical of seafaring mobilities, Ingold (2007) correctly remarks, but they are rife with opportunities to change our understanding of mobility constellations across multiple contexts, and it is for this reason that I hope a better empirical understanding of island and coastal mobilities — which this paper has provided — will be of use to many geographers.

\section{Acknowledgment}


This research was made possible by a Standard Research Grant from the Social Sciences and Humanities Research Council of Canada. My gratitude is also extended to April Vannini for her research assistance.

\section{References}

Adey, P. (2006) Airports and air-mindedness, Social \& Cultural Geography, 7: 343-363.

Adey, P. (2009) Mobility. London: Routledge.

Adey, P. (2010) Aerial Life. London: Blackwell.

Aldred, R. (2010) On the outside, Social \& Cultural Geography, 11: 35-52.

Avraham, E. and A. First (2006) Media, power and space, Social \& Cultural Geography, 7: 7186.

Baldacchino, G. (2007a) Introducing a world of islands, in G. Baldacchino (ed.) A World of Islands, 1-32. Charlottetown, PEI: Institute of Island Studies.

Baldacchino, G. (2007b) A World of Islands. Charlottetown, PEI: Institute of Island Studies.

Baldacchino, G. (2007c) Bridging Islands. Charlottetown, PEI: Acorn Press. 
Baldacchino, G. (2007d) Introduction, bridges and islands in G. Baldacchino (ed.) Bridging Islands, 1-14. Charlottetown, PEI: Acorn Press.

Binnie, J., T. Edensor, J. Holloway, S. Millington, C. Young (2007) Mundane mobilities, banal travels, Social \& Cultural Geography, 8: 165-174.

Bissell, D. (2008) Comfortable bodies, sedentary affects, Environment \& Planning A 40: 16971712.

Bissell, D. (2009) Conceptualising differently-mobile passengers, Social \& Cultural Geography 10: 173-195.

Büscher, M. and Urry, J. (2009) Mobile methods and the empirical, European Journal of Social Theory 12: 99-116.

Carlquist, S. (1965) Island Life. New York: Natural History Press.

Cass, N., Shove, E., and Urry, J. (2005) Social exclusion, mobility, and access, The Sociological Review 53: 539-555.

Clark, E., Johnson, K., Lundholm, M., and Malmberg, G. (2007) Gentrification and space wars, in G. Baldacchino (ed.) A World of Islands, 483-512. Charlottetown, PEI: Institute of Island Studies. 
Crang, M. (2002) Between places, Environment \& Planning A 34: 569-574.

Connell, J. and King, R. (1999) Island migration in a changing world, in R. King and J. Connell (eds) Small Worlds, Global Lives, 1-26. London: Pinter.

Cosgrove, D. (2007) Island passages, in G. Baldacchino (ed.) Bridging Islands, 15-28.

Charlottetown: Acorn Press.

Cresswell, T. (2010) Towards a politics of mobility, Environment \& Planning D 28: 17-31.

de Certeau, M. (1984) The Practice of Everyday Life. Berkeley: University of California Press.

Farrington, J. and Farrington, C. (2005) Rural accessibility, social inclusion and social justice, Journal of Transport Geography 13: 1-12.

Graham, S. (2002) FlowCity, Journal of Urban Technology, 9: 1-20.

Graham, S. and S. Marvin (2001) Splintering Urbanism, London: Routledge.

Jensen, B. (2004) Case study Sukhumvit line_-or learning from Bangkok, in T. Neilsen, N. Albertsen, and P. Hammerham (eds.) Urban Mutations, 183-216. Aarhus: Folag. 
Hau'ofa, E. (1994) Our sea of islands, The Contemporary Pacific 6: 148-161.

Hine, J. (2007) Travel demand management and social exclusion, Mobilities 2: 109-120.

Hine, J. and Mitchell, F. (2001) Better for everyone? Travel experiences and transport exclusion, Urban Studies 38: 319-332.

Howitt, R. and M. Hillman (2009) Environmental justice and the commons, in S. Smith, R. Pain, S. Marston, and J.P. Jones (eds.) The SAGE Handbook of Social Geographies, 455-473. London: SAGE.

Hunter, M. and C. Corbin (2007) 'Built for going away:' in G. Baldacchino (ed.) Bridging Islands, 67-84. Charlottetown, PEI: Acorn Press.

Ingold, T. (2000) The Perception of the Environment. London: Routledge.

Ingold, T. (2007) Lines. London: Routledge.

Kabachnik, P. (2009) To choose, fix, or ignore culture?, Social \& Cultural Geography 10: 461479.

Källgård, A. (2007) Sweden, islands, and bridges, G. Baldacchino (ed.) Bridging Islands 251260. Charlottetown, PEI: Acorn Press. 
Knowles, R. (2000) The Great Belt fixed link and Denmark's transition from inter-island sea to land transport, Geography 85: 345-354.

Knowles, R. (2004) Impacts of privatizing Britain's rail passenger service—franchising, refranchising and Ten Year Transport Plan targets, Environment \& Planning A 36: 2065-2087.

Law, J. (2002) Objects and spaces, Theory, Culture \& Society 19: 91-105.

Michael, M. (2000) These boots are made for walking..., Body \& Society, 6: 107-126.

Middleton, J. (2010) Sense and the city, Social \& Cultural Geography, 11: 575-596.

Onmacht, T. Maksim, H. and Bergman, M. (eds) (2009) Mobilities and Inequality. Surrey: Ashgate.

Rajé, F. (2007) The lived experience of transport structure: an exploration of transport's role in people's lives, Mobilities 2: 51-74.

Robbins, P. and B. Marks (2009) Assemblage Geographies, in S. Smith, R. Pain, S. Marston, and J.P. Jones (eds.) The SAGE Handbook of Social Geographies, 176-194. London: SAGE.

Royle, S. (2001) A Geography of Islands: Small Island Insularity. London: Routledge. 
Schönfelder, S., Rich, J., Nielsen, O., Würtz, C., and Axhausen, K. (2007) Road pricing and its consequences for individual travel patterns, Mobilities 2:75-98.

Shaw, J. (2000) Competition, Regulation, and the Privatisation of British Rail. Aldershot: Ashgate.

Shaw, J., R. Knowles, and I. Docherty (2008) Transport governance and ownership, in R. Knowles, J. Shaw, and I. Docherty (eds.) Transport Geographies, 62-80. Malden: Blackwell.

Sheller, M. (2007) Bodies, cybercars, and the mundane incorporation of automated mobilities, Social \& Cultural Geography 8: 175-197.

Tanner, E. (1997) When Things Bite Back. New York: Vintage.

Thrift, N. (2008) Non-Representational Theory. London: Routledge.

Urry, J. (2007) Mobilities. New York: Polity.

Watts, L. (2008) The art and craft of train travel, Social \& Cultural Geography 9: 711-726.

Watts, L. and Urry, J. (2008) Moving methods, travelling times, Environment \& Planning D 26: 860-874. 
Woodward, K. and J. Lea (2009) Geographies of affect, in S. Smith, R. Pain, S. Marston, and J.P. Jones (eds.) The SAGE Handbook of Social Geographies, 154-175. London: SAGE. 